\title{
El origen judeocristiano de la música en la obra de Isidoro de Sevilla
}

\author{
The Judaeo-Christian Origin of Music \\ in the Works of Isidore of Seville
}

Isidoro de Sevilla expone en su Chronica una serie de interesantes noticias sobre los inventores de la música basándose en el Chronicon de Jerónimo. Entre estas noticias destaca una por su ubicación, su contenido y su originalidad, ya que atribuye la creación de la música a un personaje bíblico, desligándose en este caso de Jerónimo, su fuente, quien atribuye a la música un origen pagano relacionado con la mitología grecolatina. Posteriormente, el obispo hispalense vuelve a tratar el tema en sus Etimologías, exponiendo dos nuevas noticias sobre los inventores bíblicos de la música cuyo contenido vuelve a variar de manera sensible en relación a lo expuesto en la noticia señalada de su Chronica. En este artículo se pretende dar una explicación a las variaciones de contenido observadas en estas tres noticias (que, sorprendentemente, han pasado inadvertidas para casi la totalidad de la crítica) partiendo del análisis del pensamiento histórico-musical isidoriano, sus métodos de trabajo y el contexto cultural tardoantiguo.

Palabras clave: Isidoro de Sevilla, Jubal, Tubal, música, pensamiento musical, Chronica, Crónica Universal, Etymologiae, Etimologías.

In his Chronica, Isidore of Seville outlines a series of interesting stories about the inventors of music based on Jerome's Chronicon. One of these stories stands out for its location, content and originality, as it attributed the creation of music to a biblical figure. This differs from Jerome, his source, who cites music's pagan origin related to Graeco-Latin mythology. The Sevillian bishop subsequently revisits the subject in his Etymologiae, outlining two new stories about the biblical inventors of music whose content, once again, varies substantially in relation to what was set out in his Chronica. This article aims to provide an explanation for the variations in the content in these three stories (which, surprising$1 y$, have gone unnoticed in almost all critical scholarship) based on the analysis of Isidorian historical-musical thought, his work methods and the cultural context of Late Antiquity.

Keywords: Isidore of Seville, Jubal, Tubal, music, musical thought, Chronica, Chronica Majora, Etymologiae, Etimologies.

Este trabajo parte de dos premisas que han pasado prácticamente inadvertidas para la crítica y que, hasta ahora, no han sido analizadas por la bibliografia existente. En primer lugar, Isidoro atribuye en su Chronica un origen bíblico a la música, indicando expresamente que Jubal es su creador. Se trata de una noticia capital debido a su excepcionalidad si la comparamos con el resto de las 
ocho grandes noticias musicales que el obispo hispalense expone en esta obra sobre los orígenes de la música, todas dedicadas a personajes paganos asociados a la mitología clásica. Además, este hecho llama más la atención cuando se comprueba que cinco de estas grandes noticias musicales (además de otras muchas menores) están prácticamente copiadas del Chronicon de Jerónimo, modelo y fuente de Isidoro, donde no se encuentra la más mínima alusión a Jubal (ni a ningún personaje bíblico) como creador de la música.

La segunda de estas premisas ignoradas por la crítica está constituida por el siguiente hecho: poco tiempo después de atribuir a Jubal la invención de la música en su Chronica, el doctor hispalense atribuye en dos noticias de las Etimologías $^{1}$ el origen de la música a Tubal, otro personaje bíblico.Varía así el contenido de su versión anterior y, lo que llama más la atención, mantiene ambas versiones (la de Jubal y la de Tubal) en sendas obras hasta su muerte, pues la atribución de la invención de la música a Jubal aparece también en la segunda edición de la Chronica, de la que hablaré más adelante.

Por tanto, el objetivo de este artículo es doble. En primer lugar, analizar los motivos que condujeron a Isidoro a presentar esa novedad en su Chronica en relación al texto de Jerónimo, así como las posibles fuentes en las que se pudo haber basado para su redacción. En segundo lugar, analizar los motivos que condujeron al doctor hispalense a variar el texto de sus Etimologías en relación a lo que había expuesto previamente en su Chronica, así como las posibles fuentes en las que se pudo haber basado para realizar ese cambio. Además, se concluye con un último apartado en el que se argumenta por qué Isidoro mantuvo estas dos noticias que se contradicen en ambas obras hasta su muerte.

\section{Jubal como inventor de la música}

La noticia isidoriana de Jubal como inventor de la música se encuentra en una obra de carácter histórico, por lo que para poder argumentar los motivos que condujeron a Isidoro a incluirla en su obra, se ha de partir necesariamente del pensamiento histórico y de la obra histórica isidoriana.

\section{La obra historiográfica de Isidoro de Sevilla}

La faceta historiográfica de Isidoro de Sevilla es una de las más notables de su poliédrica personalidad, ya que es cultivada en varias obras, fundamentalmente en dos, la Chronica ${ }^{2}$, la obra principal estudiada en este trabajo, y las Historiae gothorum,

\footnotetext{
${ }^{1}$ Debido a la familiaridad de su nombre castellano, utilizo esta nomenclatura en lugar de la latina.

${ }^{2}$ La edición crítica de referencia es la de José Carlos Martín: Isidori Hispalensis Chronica, Turnhout, Corpus Christianorum Series Latina (CCSL) 112, 2003. También se pueden consultar ediciones del texto en Jacques Paul Migne (ed.): Patrologia Latina (PL), vol. 83, col. 1017-1058 (quien recoge la edición del corpus isidoriano realizada por Faustino Arévalo [Roma, 1797-1803]); y en Theodor Mommsen: Chronica
} 
wandalorum et sueborum ${ }^{3}$, que trata la historia de los visigodos, vándalos y suevos (cada una de manera separada) hasta el reinado de Sisebuto (612-621), en la primera edición, y de Suintila (621-631), en la segunda. A estas obras habría que añadir De viris illustribus ${ }^{4}$, obra que también tiene una considerable inclinación historiográfica5; y el último y muy extenso capítulo (el 39) del Libro V de las Etimologías ${ }^{6}$. Dicho capítulo guarda una estrecha relación con la propia Chronica isidoriana, tanto en el estilo, como en los datos que ofrece; aunque no hay información relacionada con las noticias musicales que se tratan en la Chronica y en este artículo.

Minora 2.2. Monumenta Germaniae Historica (MGH), Auctores Antiquissimi, Tomus XI, pp. 424-481. Esta última ofrece las dos versiones de la Chronica que comentaré más adelante. Para una traducción castellana con una completa introducción, véase José Carlos Martín: "La Crónica Universal de Isidoro de Sevilla: Circunstancias históricas e ideológicas de su composición y traducción de la misma", Iberia, 4, 2001, pp. 199-236.

${ }^{3}$ La edición crítica de esta obra es la realizada por Cristóbal Rodríguez Alonso: Las historias de los godos, vándalos y suevos de Isidoro de Sevilla. Estudio, edición crítica y traducción, León, Centro de Estudios e Investigación San Isidoro, 1975. En esta obra se recogen la edición crítica de las dos ediciones isidorianas existentes, así como la introducción, traducción de las mismas y las notas correspondientes. Además, esta obra se encuentra en PL 83, 1057-1082.

${ }^{4}$ Carmen Codoñer: El "De viris illustribus" de Isidoro de Sevilla. Estudio y edición crítica, Salamanca, Ediciones Universidad, 1964. También ha sido editada posteriormente por Valeriano Yarza Urquilloa, Carmen Codoñer: Ildefonsi Toletani episcopi De virginitate sanctae Mariae, De cognitione baptismi, De itinere deserti, De viris illustribus, Turnhout, Breposls, CCSL 114A, 2007. Es importante destacar que de esta obra isidoriana existen dos recensiones, una mayor y otra menor. La mayor se encuentra dentro de la edición recogida por J. P. Migne (PL 83, cols. 1081-1106). Actualmente se da por hecha la no autoría isidoriana de varios capítulos de la mayor, teniéndose la menor como la original.

${ }^{5}$ De viris illustribus es una obra compuesta por 33 breves noticias de carácter biográfico de personajes cristianos relevantes por su labor literaria principalmente, aunque, en un segundo plano, también se destacan otros aspectos de carácter doctrinal, pastoral o moral. Se trata de una obra basada en una tradición literaria anterior al igual que ocurre con otros textos isidorianos. Jerónimo (también siguiendo la tradición clásica, ejemplificada en el perdido De viris illustribus de Suetonio, influyente historiador y biógrafo romano del siglo II) fue el primero entre los cristianos en escribir una gran obra de estas características con el objetivo de destacar a los escritores e intelectuales cristianos más ilustres, quienes solían quedar en un segundo plano en comparación con los paganos. A este autor le siguió Genadio de Marsella, teólogo e historiador que vivió en la segunda mitad del siglo V. Tras él, aparece Isidoro, quien se centra principalmente en personajes de Hispania. Así, de las 33 biografías que encontramos, doce pertenecen a personajes hispanos. Para la edición de la obra de Jerónimo, véase W. Herding (ed. crít.): Hieronymi De viris illustribus liber, Leipzig, Bibliotheca Scriptorum Graecorum et Romanorum Teubneriana (BT), 1879. Para la edición de la obra de Genadio de Marsella (también incluye la de Jerónimo), véase Ernest Cushing Richardson (ed. crít.): Hieronymus. Liber de viris illustribus. Genadius. De viris illustribus. Leipzig, BT, 1896.

${ }^{6}$ La edición de referencia del Libro V es la de Valeriano Yarza Urquilloa, Francisco Javier Andrés Santos: Isidorus Hispalensis. Etymologiae V. Introducción, edición crítica, traducción y notas, París, Les Belles Lettres, Auteurs Latins Du Moyen Âge (ALMA), 2013. Para la traducción castellana, se puede consultar José Oroz Reta, Manuel Antonio Marcos Casquero (eds.), Manuel Cecilio Díaz y Díaz (intr.): San Isidoro de Sevilla. Etimologías. Edición bilingüe, Madrid, Biblioteca de Autores Cristianos (BAC), 2009 (1982). 


\section{La Chronica de Isidoro. Fuentes, modelos y circunstancias de su composición}

Se trata de una crónica universal que sigue la tradición literaria anterior, en la que se exponen los principales nombres y hechos acontecidos a lo largo de la historia desde la creación del mundo hasta, en este caso, la época del propio Isidoro.

Como ya se ha indicado, la obra está basada fundamentalmente en el Chronicon de Jerónimo ${ }^{7}$, autor que constituye una de las mayores influencias en el pensamiento y la obra de Isidoro de Sevilla, destacando, desde el punto de vista que nos ocupa, sus obras históricas. Jerónimo realizó la traducción, revisión y complementación (en este último aspecto especialmente desde el año 326 al 379) del Cronicón de Eusebio de Cesarea ${ }^{8}$. El Cronicón de Eusebio se encuentra dividido en dos partes. La primera parte es una historia universal organizada según las grandes naciones de la Antigüedad desarrolladas en Oriente Medio y el Mediterráneo. La segunda parte está constituida por una especie de tablas (similares a los viejos anales romanos en finalidad y brevedad) en las que se establecen distintos sincronismos entre las diferentes culturas descritas en la primera parte de la obra. Las noticias que Isidoro expone sobre la música basándose en el Chronicon de Jerónimo pertenecen a esta segunda parte.

Existen dos versiones de la Chronica isidoriana 9: una primera versión escrita aproximadamente en tiempos del rey Sisebuto y promovida por este (fechada en torno al 615-616); y otra posterior, corregida y ampliada, escrita en tiempos del rey Suintila (fechada en torno al 626). Estas dos diferentes redacciones fueron motivadas por el curso de los acontecimientos políticos ${ }^{10}$.

${ }^{7}$ Para la edición crítica del Chronicon de Jerónimo véase Rudolf Helm: Eusebius Caesarensis. Werke. Band 7. Die Chronik des Hieronymus. Hieronymi Chronicon. Berlín, De Gruyter (Die Griechischen Christlichen Schriftsteller der ersten drei Jahrhunderte [GCS] 47), 2013. No obstante, para este artículo he consultado el texto en PL 27, col. 11-508.

${ }^{8}$ La edición del Chronicon de Eusebio se encuentra junto con la edición de la obra homónima de Jerónimo citada en la nota anterior.

${ }^{9}$ Como también existen, y por los mismos motivos, dos versiones de las Historiae gothorum, wandalorum et sueborum.

${ }^{10}$ Para una explicación detallada de los acontecimientos, véase la introducción a la obra anteriormente citada de J. C. Martín: "La Crónica Universal...". Además, el artículo de José Miguel Alonso-Núñez: "Aspectos del pensamiento historiográfico de San Isidoro de Sevilla", Aeuum inter utrumque. Mélanges offerts à F. Sanders, M. van Uytfanghe, R. Demeulenaere (eds.), Steenbrugge, 1991, pp. 1-10; la interesante visión de Marc Reydellet: "Les intentions idéologiques et politiques dans la Chronique d'Isidore de Séville", Mélanges d'Archéologie et d'Histoire de l'École Fraçaise de Rome, 87, 1970, pp. 363-400; el completo artículo de José Luis Romero: "S. Isidoro de Sevilla, su pensamiento político-histórico y sus relaciones con la historia visigoda", Cuadernos de Historia de España, 8, 1947, pp. 6-71; Eustaquio Sánchez Salor: "El providencialismo en la historiografía cristiano-visigótica de España", Anuario de Estudios Filológicos, 5, 1982, pp. 172-192; el artículo de F. E. de Tejada: "Ideas políticas y jurídicas en San Isidoro de Sevilla", Revista 
En relación al posicionamiento político-histórico-ideológico de Isidoro de Sevilla a la hora de componer estas crónicas se han postulado varias interpretaciones. Estas posiciones se pueden encuadrar, con ciertos matices, dentro de tres grandes grupos. Hay algunos autores que consideran a Isidoro un amante de la idea de Hispania como nación, como un lugar en el mundo más relevante que sus propios moradores ${ }^{11}$; mientras que otros lo consideran un escritor al servicio del poder visigodo ${ }^{12}$. Por otra parte, hay una corriente, que bien se puede considerar intermedia, basada en la idea de que Isidoro creía firmemente en la unión de visigodos e hispano-romanos y los consideraba parte de un mismo pueblo ${ }^{13}$.

Independientemente de estos puntos de vista, lo que parece claro es que Sisebuto, el rey culto que las mandó componer, y el propio Isidoro eran conscientes de la importancia de dar testimonio de la existencia y la grandeza de este reino visigodo en la historia, con especial énfasis en la transcendencia de su reinado, que perduraría así en el devenir de los tiempos.

Por otro lado, aparte de esta motivación de carácter filosófico-histórico, se puede observar también una inclinación de carácter político. Hasta el momento las grandes obras historiográficas tenían una visión del mundo primero griega y luego romana, aspecto que continuó con las grandes obras historiográficas cristianas. De ahí la importancia de escribir una historia, no con una visión romana del mundo, sino bajo el punto de vista visigodo e hispano. Esto no lo consiguieron las crónicas de Hidacio de Chaves ${ }^{14}$ y Juan de Bíclaro ${ }^{15}$, ya que tienen un carácter demasiado regionalista ${ }^{16}$. Este carácter mixto entre la historia universal (desde el punto de vista visigodo) y la hispana, lo consiguió por primera vez Isidoro de Sevilla.

General de Legislación y Jurisprudencia, 41, 1960, pp. 225-258; y la visión de Luis Vázquez de Parga: "Notas sobre la obra histórica de San Isidoro", Isidoriana, Estudios sobre san Isidoro de Sevilla en el XIV centenario de su nacimiento, Manuel Cecilio Díaz Díaz (ed.), León, Centro de Estudios San Isidoro, 1961, pp. 99-106.

${ }^{11}$ M. Reydellet: "Les intentions...", pp. 514-516.

${ }^{12}$ E. Sánchez Salor: "El providencialismo...., p. 184.

${ }^{13}$ Tal y como ocurre con J. C. Martín: “La Crónica Universal...”, pp. 200-202. También Jacques Fontaine: Génesis y originalidad de la cultura hispánica en tiempos de los visigodos, Madrid, Ediciones encuentro, 2002 [Turnholt, Brepols, 2000], p. 281. Fontaine no solo comparte esta idea, sino que va más allá extendiéndola a todos los miembros de una generación: "la consigna de esta generación fue, en todos los ámbitos, la de unificación -territorial, política, religiosa, cultural-, bajo el poder de un solo monarca que residiera en Toledo".

${ }^{14}$ Para la edición crítica de la obra, véase Julio Campos Ruiz: Idacio, obispo de Chaves. Su cronicón. Introducción, texto crítico, versión española y comentario, Salamanca, Ediciones Calasancias, 1984.

${ }^{15}$ Para la crónica de Juan de Bíclaro, véase Julio Campos Ruíz: Juan de Bíclaro, obispo de Gerona. Su vida y su obra, Madrid, CSIC, 1960.

${ }^{16}$ La crónica de Juan de Bíclaro es la más importante de todas las que se escribieron en el período en Hispania después de la de Isidoro de Sevilla, tanto por su calidad como por la importancia de su contenido. Además de las ediciones de las dos crónicas (la de Juan de Bíclaro y la de Hidacio de Chaves), ya citadas, véase el artículo de Fernando Álvarez García: "Tiempo, religión y política en el Chronicon de 


\section{Las referencias musicales en la Chronica}

Isidoro de Sevilla expone en su Chronica una serie de interesantes noticias sobre los orígenes de la música y sus inventores, así como sobre grandes músicos y logros musicales destacables del pasado, demostrando, una vez más, su erudición y su afición por las antigüedades. Evidentemente, no es una historia de la música al uso (en el sentido moderno del término); pero sí escribe una crónica universal siguiendo, tal y como se ha indicado, la tradición literaria anterior, en la que se exponen los principales nombres y hechos acontecidos a lo largo de la historia desde la creación del mundo hasta, en este caso, la época del propio Isidoro. Entre esas noticias de carácter general se encuentran las puramente musicales, que, además, proporcionan una idea bastante interesante de la concepción isidoriana de la historia de la música.

Estas referencias a la música constituyen un corpus relativamente numeroso en contra de lo que pudiera parecer si tenemos en cuenta la temática de la obra. De hecho, es una de las obras de Isidoro con más referencias musicales, estando la mayoría de ellas inspiradas o basadas en el Chronicon de Jerónimo. Al estar redactada en forma de anuario, con frases de duración variable (más bien cortas) que describen lo más reseñable de cada año, las menciones a la música suelen coincidir con la información dada en un año concreto; por tanto, son referencias con una gran importancia histórica, aunque se encuadren dentro del hilo narrativo general del texto cuya finalidad, obviamente, no es musical. A continuación se desglosan en el siguiente cuadro, indicando, cuando procede, la noticia del Chronicon de Jerónimo en la que debió inspirarse Isidoro. En ocasiones se puede apreciar una gran dependencia del texto jeronimiano ${ }^{17}$ :

\footnotetext{
Ioannis Biclarensis", España Medieval, 20, 1997, pp. 9-30; y el estudio de Pedro Juan Galán Sánchez: El género historiográfico de la Chronica. Las crónicas hispanas de la época visigoda, Cáceres, Universidad de Extremadura, 1994.

${ }^{17}$ Siguiendo la edición mencionada de J. C. Martín Iglesias (Isidori Hispalensis Chronica... CCSL 112), siempre que no se indique nada, se da por hecho que esa noticia se encuentra en las dos versiones de la Chronica. En caso de que solo se encuentre en una versión, se indicará cuál. También se exponen las traducciones realizadas por el propio Martín Iglesias en su artículo "La Crónica Universal...".
} 
Cuadro 1. Referencias a la música en la Chronica de Isidoro y el Chronicon de Jerónimo

\begin{tabular}{|c|c|c|c|}
\hline \multicolumn{2}{|r|}{ ISIDORO } & \multicolumn{2}{|r|}{ JERÓNIMO } \\
\hline Capítulo & Referencia & Columna & Referencia \\
\hline $\begin{array}{l}\text { Cap. } 14 \text {, } \\
\text { año } 1454\end{array}$ & $\begin{array}{l}\text { Hac quoque aetate Iubal ex genere Cain artem } \\
\text { musicam repperit, cuius etiam frater Tubalcain } \\
\text { aeris ferrique inuentor fuit }{ }^{18}\end{array}$ & & \\
\hline $\begin{array}{l}\text { Cap. } 51 \text {, } \\
\text { año } 3688\end{array}$ & $\begin{array}{l}\text { Tunc primi Coretes et Coribantes modulatam in } \\
\text { armis saltationem et consonam inuenerunt }{ }^{19}\end{array}$ & $285-286$ & $\begin{array}{l}\text { Curetes et corybantes Cnoson condiderunt, qui } \\
\text { modulata et inter se concientem in armis saltatio- } \\
\text { nem repererunt }\end{array}$ \\
\hline $\begin{array}{l}\text { Cap. } 63-64 \text {, } \\
\text { año } 3795\end{array}$ & $\begin{array}{l}\text { Per idem tempus primi Linus et Anfion apud } \\
\text { Graecos in musica arte claruerunt. Ideeique } \\
\text { Dactili ferrum eo tempore inuenerunt }{ }^{20}\end{array}$ & 297 & $\begin{array}{l}\text { Linus thebaeus et Zethus et Amphion in musica } \\
\text { arte clarescunt }\end{array}$ \\
\hline $\begin{array}{l}\text { Cap. } 72, \\
\text { año } 3875\end{array}$ & $\begin{array}{l}{[. . .] \text { de Anfione, quod citharae cantu lapides et }} \\
\text { saxa commonerit }{ }^{21}\end{array}$ & 305 & $\begin{array}{l}\text { Amphion Tebis in Achaia regnavit quem ferum } \\
\text { fabulae Graecorum cantu citharae saxa movisse. } \\
\text { Fuerunt autem duro corde, et ut ita dicam, saxei } \\
\text { quidam auditores }\end{array}$ \\
\hline $\begin{array}{l}\text { Cap. } 74 \text {, año } \\
\text { 3915, segun- } \\
\text { da versión }\end{array}$ & $\begin{array}{l}\text { Per idem tempus Apollo citharam condidit, et } \\
\text { medicinae artem invenit }{ }^{22}\end{array}$ & & \\
\hline $\begin{array}{l}\text { Cap. } 77 \mathrm{a}, \\
\text { año } 3955, \\
\text { segunda } \\
\text { versión }\end{array}$ & $\begin{array}{l}\text { Hac aetate alter Mercurius lyram repperit, et } \\
\text { Orpheo tradidit }{ }^{23}\end{array}$ & & \\
\hline $\begin{array}{l}\text { Cap. } 77 b \text {, } \\
\text { año } 3956, \\
\text { segunda } \\
\text { versión }\end{array}$ & 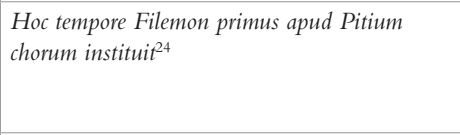 & 308 & $\begin{array}{l}\text { Philammon Delphius divinus nobilis habetur, } \\
\text { qui primus apud Phytium chorum constituit }\end{array}$ \\
\hline $\begin{array}{l}\text { Cap. } 79 \text {, } \\
\text { suprimido } \\
\text { en la segun- } \\
\text { da versión, } \\
\text { año } 3956\end{array}$ & $\begin{array}{l}\text { Orfeus Trax Linusque magister Herculis artis } \\
\text { musicae inuentores clari habentur }\end{array}$ & 309 & $\begin{array}{l}\text { Linus magister alterius Herculis omnibus notus } \\
\text { efficitur }\end{array}$ \\
\hline
\end{tabular}

Además de estas alusiones musicales, existen otras de gran interés por las temáticas que abarcan, muy relacionadas con la música. Y es que en la Chronica aparecen muchos de los grandes poetas griegos y romanos desde Homero, al que considera como el primer poeta allá por el año 4125 a. C. Lo mismo ocurre con los filósofos, los historiadores e incluso algunos pintores. En definitiva, una gran serie de personajes ilustres de la vida política y cultural de la Antigüedad, tanto pagana como cristiana, desfilan por la Chronica isidoriana.

18 "También en esta época Jubal, del linaje de Caín, descubrió el arte de la música y su hermano Tubalcaín fue el inventor del bronce y el hierro".

19 "Por entonces los curetes y los coribantes inventaron los primeros una danza con armas melodiosa y armoniosa".

20 "En esa misma época, Lino y Anfión sobresalieron los primeros entre los griegos en el arte musical y los sacerdotes de Cibeles del monte Ida descubrieron en esa misma época el hierro".

21 "[...] de Anfión, que este con el canto de su cítara conmovía a piedras y rocas".

22 "Por esa misma época Apolo inventó la cítara y descubrió el arte de la medicina".

23 "En esta época otro Mercurio inventó la lira y se la entregó a Orfeo".

24 "Por esos días, Filamón, formó el primero el coro en Pitio".

25 "El tracio Orfeo y Lino, maestro de Hércules, inventores del arte musical son tenidos por hombres ilustres". 


\section{Jubal como creador de la música. Originalidad de la noticia isidoriana}

Como ya se ha dicho, Isidoro atribuye a la música un origen judeocristiano, un origen bíblico. El obispo hispalense, basándose en la Biblia (Ge.4.21), considera a Jubal, de la estirpe de Caín, como el primer músico de la historia y el padre de todos los músicos, siendo el primero de estos en aparecer en su Chronica (cap. 14, año 1454): Hac quoque aetate Iubal ex genere Cain artem musicam repperit ${ }^{26}$.

Este origen bíblico de la música no solo supone una novedad en la obra de Isidoro si lo comparamos con el Chronicon de Jerónimo (y, probablemente, con la obra perdida de Eusebio), sino que, directamente, Isidoro ha de ser considerado el iniciador de esta tradición literaria, pues todo parece indicar que la atribución de la creación de la música a Jubal no se observa en ningún texto técnico musical latino anterior a Isidoro y apenas y se observa en la literatura patrística griega ${ }^{27}$. De hecho, la obra de James Mckinnon, Music in Early Christian Literature ${ }^{28}$, corrobora esta tendencia, pues entre los autores cristianos citados de estos primeros siglos que tratan los orígenes de la música,-Taciano

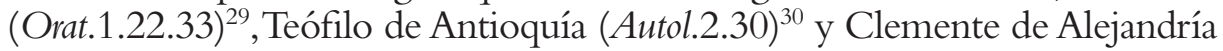
$(\text { Strom.1.16.76) })^{31}-, \tan$ solo Teófilo señala a Jubal como el creador de la música; y, evidentemente, Isidoro no leyó a un autor tan lejano en la distancia cultural y en el tiempo como Teófilo.

Por tanto, estamos ante una innovación isidoriana realizada ex profeso basándose en su conocimiento de la Biblia. Sin embargo, para argumentar que esta es una novedad isidoriana debemos acudir a otros aspectos relacionados con el mundo cultural del obispo hispalense, así como con su pensamiento y su obra.

26 "También en esta época Jubal, del linaje de Caín, descubrió el arte de la música".

${ }^{27}$ Para Jubal y su relación con la música, véanse Judith Cohen: "Jubal in the Middle Ages", Yûbal/ Yuval: Studies of the Jewish Music Research Centre III, Jerusalem, The Magnes Press-The Hebrew University, 1974, pp. 83-99, para la evolución musical de este personaje a lo largo de la Edad Media; Davide Daolmi: "Jubal, Pythagoras and the Myth of the Origin of Music. With Some Remarks Concerning the Illumination of Pit (It. 568)", Philomusica on- line, 16, 2017, pp. 1-42, para la evolución posterior en la historia del arte; y, sobre todo, James Mckinnon: "Jubal uel Pythagoras, quis sit inuentor musicae: Thoughts on Musical Historiography from Boethius to Burney", The Musical Quarterly, 64, 1978, pp. 1-28, quien centra esta controversia en la evolución posterior del pensamiento musical, especialmente dentro del ámbito de la patrística.

${ }^{28}$ James Mckinnon (ed.): Music in Early Christian Literature, Cambridge, Cambridge University Press, 2012.

${ }^{29}$ Para la edición crítica de esta obra, véase Miroslav Marcovich: Tatian. Oratio ad Graecos. Berlín-Nueva York, De Gruyter (PTS -Patristische Texte und Studien-43), 1995. Para una traducción castellana, véase el estudio de José Ramón del Canto Nieto: Taciano. Discurso contra los griegos, Madrid, Akal, 2016.

${ }^{30}$ La edición de la obra se puede ver en M. Marcovich: Theophilus Antiochenus. Ad Autolycum, Berlín-Nueva York, De Gruyter (PTS -Patristische Texte und Studien-44), 1995.

${ }^{31}$ La edición de sus obras se puede ver en O. Stählin, L. Früchtel, U. Treu: Clemens Alexandrinus. Opera, Leipzig-Berlín, GCS (12, 15, 17, 39), 1905, 1936, 1960, 1972. Para la traducción del primer libro de los Stromata, citado en el texto, véase la traducción de Marcelo Merino Rodríguez: Stromata I. Cultura y religión. Introducción, traducción y notas, Madrid, Ciudad Nueva, 1996. 


\section{Las motivaciones isidorianas}

Los motivos que condujeron a Isidoro a incluir la noticia relativa a Jubal en su Chronica se pueden argumentar desde dos puntos de vista. Una primera posición con un carácter más polémico y cultural y una segunda de carácter más teológico y cronológico.

En relación a la motivación polémica y cultural, hay que destacar un hecho fundamental: Isidoro es plenamente consciente de la importancia de situar la cultura judeocristiana a un nivel superior $\mathrm{o}$, al menos, al mismo nivel que la cultura grecolatina pagana y, por eso, partiendo de sus conocimientos bíblicos, considera y expone en primer lugar, que la música tuvo unos orígenes judeocristianos. Por tanto, Isidoro antepone los orígenes bíblicos a los orígenes narrados en la mitología clásica. Del mismo modo, también es igualmente consciente de la importancia de relacionar o "conciliar" aspectos de ambas culturas, aunque siempre, como acabo de indicar, intentando supeditar los aspectos de la cultura pagana a la cristiana.

Este hecho no es exclusivo del ámbito musical y se puede extender a otros campos y disciplinas intelectuales tratados por Isidoro, cuyo caso más paradigmático, y también más extremo dentro del corpus isidoriano, lo constituye De natura rerum ${ }^{32}$. En esta obra se dan distintas explicaciones de fundamentación cristiana a cada uno de los fenómenos astronómicos expuestos, fenómenos que ya gozaban de una explicación científica pagana en la rica tradición que sobre este tema se desarrolló en la literatura grecolatina ${ }^{33}$.

Este interés tampoco es exclusivo de la época de Isidoro de Sevilla y, tal y como se puede observar en otras disciplinas fundamentales, responde a una tradición anterior. De hecho, el interés de la historiografia por igualar la cultura judeocristiana a la grecolatina ya se puede apreciar en la obra comentada de Eusebio-Jerónimo (interés que continúa el obispo hispalense en su Chronica), donde tratan de relacionar cronológicamente las distintas culturas a través de las tablas, igualando los méritos de unas y otras. Este aspecto también lo podemos observar en la propia finalidad del De viris illustribus de Jerónimo, quien desea destacar la labor de los grandes nombres del cristianismo e igualarlos así en gloria intelectual y moral a los del paganismo (trabajo que sirve de inspiración al obispo hispalense para escribir su obra homónima).

El propio Isidoro refleja esta idea de manera explícita cuando expone su pensamiento historiográfico en las Etimologías. Así, por ejemplo, al hablar de los primeros escritores de historia afirma (Etym.1.42.1) ${ }^{34}$ : Historiam

\footnotetext{
${ }^{32}$ Ineludible resulta la edición crítica de referencia de esta obra con importante aparato crítico e introducción: J. Fontaine (ed. crít.): Isidore de Seville. Traité de la nature, Burdeos, Féret et fils, 1960. Además, también se puede consultar PL 83, 963-1018. También existe otra edición con introducción y traducción al castellano realizada por Antonio Laborda: Isidorus Hispalensis. De natura rerum. Estudio, análisis y traducción, Madrid, Instituto Nacional de Estadística, 1996.

${ }^{33}$ Véase J. Fontaine: Isidore de Seville. Traité de la nature..., pp. 11-13.

${ }^{34}$ No existe edición crítica del Libro I en la colección ALMA. Utilizo, por tanto, la edición clásica de Lindsay.
} 
autem apud nos primus Moyses de initio mundi conscripsit. Apud gentiles vero primus Dares Phrygius de Graecis et Troianis historiam edidit $t^{35}$. Isidoro trata de destacar o, al menos, igualar (aunque cita primero a Moisés y, por tanto, en cierta manera lo destaca) como inventores de la historia a un personaje capital de la cultura judeocristiana, Moisés, con un personaje (Dares, héroe homérico de la Guerra de Troya) representante de la cultura grecolatina, más rica desde el punto de vista historiográfico y científico en general.

En relación a la motivación cronológica y teológica es necesario, en primer lugar, señalar el motivo teológico evidente que subyace en todo este asunto: Isidoro sitúa a Jubal como inventor de la música y padre de todos los músicos porque tiene la verdadera convicción de que todo lo creado, incluida la música, procede de la obra de Dios; y más cuando este aspecto se encuentra de manera tan clara en la Biblia y, además, prácticamente al comienzo de la misma (Ge.4.21). Este es el motivo más importante y el que da sentido a la inclusión de Jubal en su obra. Isidoro no puede concebir que algo como la música, tan profundo y tan arraigado en la tradición y en la liturgia cristianas y, por tanto, tan cercano a Dios, tenga un origen pagano; y más cuando la Biblia habla con una claridad meridiana respecto a este asunto.

Esta última idea se comprende todavía más si analizamos el paradigma histórico-cronológico que envuelve a la Chronica, al pensamiento histórico isidoriano y, por tanto, a su concepción de la historia de la música, en el que podemos establecer dos niveles. En primer lugar, se puede observar cómo la historia isidoriana se articula siguiendo la tradicional concepción de la historia agustiniana, de evidente fundamentación y carácter bíblicos, en la que el mundo es dividido en seis edades de acuerdo con algunos hechos relevantes dentro de la propia estructura cronológica de la Biblia ${ }^{36}$. En segundo lugar, se puede comprobar la enorme influencia que ejercen algunos aspectos de la concepción de la historia de Eusebio de Cesarea, transmitida a Isidoro a través del Chronicon de Jerónimo, en el que los hechos aparecen expuestos con una estructura parecida a las de los anales romanos y en forma de tablas superpuestas en las que se establecen distintos sincronismos entre las grandes culturas de la Antigüedad (entre las que se incluye, evidentemente, la judeocristiana). Además, se observa cómo, siguiendo también a Jerónimo, Isidoro continúa con la tradición heuremática (qué personaje ha descubierto o inventado algo), tan común en los manuales y compendios de este período.

35 "Entre nosotros, el primero que escribió una historia sobre el inicio del mundo fue Moisés. Entre los gentiles, fue Dares, el frigio, que compuso una historia sobre los griegos y los troyanos".

${ }^{36}$ Primera Edad, desde la Creación hasta el Diluvio Universal. Segunda Edad, desde el Diluvio hasta el nacimiento de Abraham. Tercera Edad, desde Abraham hasta David. Cuarta Edad, desde el reinado de David hasta el cautiverio en Babilonia. Quinta Edad desde el cautiverio en Babilonia hasta el nacimiento de Cristo, con el que da comienzo a la Sexta Edad. 
Esta doble estructura cronológica, que gracias a Agustín tiene un marcado carácter bíblico y que, gracias a Eusebio-Jerónimo, relaciona la cultura judeocristiana con las grandes civilizaciones y culturas del mundo antiguo, es la que envuelve a todas las noticias sobre los orígenes y los inventores de la música. La inmensa mayoría de las noticias que expone Isidoro relacionadas con la música hacen referencia a los dioses y héroes clásicos, situándolos en la Tercera Edad agustiniana (entre las épocas de Abraham y de David) y, dentro del cómputo de años de Eusebio-Jerónimo, entre los años 3184 y 4124 . Lo mismo se puede decir de los personajes, ya históricos, relacionados con las distintas disciplinas que tangencialmente tocan a la música, situados en las tres edades del mundo siguientes, ya que llegan hasta la época del propio Isidoro (en la Chronica aparece su hermano Leandro).

Por tanto, teniendo en cuenta este paradigma histórico-cronológico y el profundo sentir religioso de Isidoro, el obispo hispalense tan solo tiene que incluir la noticia de Jubal en el lugar correspondiente siguiendo la sucesión de hechos narrada en el Génesis para demostrar así el origen bíblico de la música. Evidentemente este lugar debe estar situado en la Primera Edad del mundo agustiniana (entre la Creación y el Diluvio) y, dentro del cómputo de años de Eusebio-Jerónimo, entre el año 1454 y 1642.

\section{Tubal como inventor de la música}

Tal y como se ha indicado, pocos años después de describir en su Chronica a Jubal como el creador de la música, el obispo hispalense vuelve a tratar los orígenes de esta disciplina en dos noticias diferentes del Libro III de las Etimo$\log i ́ a^{37}$, aunque en esta ocasión describe como creador de la música a Tubal, hermanastro de Jubal por parte de padre. En la primera de estas noticias se puede leer: "Moyses dicit repertorem musicae artis fuisse Tubal, qui fuit de stirpe Cain ante dilunium" (Etym.3.15.1) ${ }^{38}$. En la segunda, Isidoro convierte a Tubal en inventor de la cítara y el salterio: "Citharae ac psalterii repertor Tubal, ut praedictum est, perhibetur"(Etym.3.21.2) ${ }^{39}$.

\footnotetext{
${ }^{37}$ Para la edición crítica de referencia actual del libro III, véase Giovanni Gasparotto, Jean-Yves Guillaumin (ed. crít.): Isidorus Hispalensis. Etymologiae III. Texte établi par G. Gasparotto (avec la collaboration de J.-Y. Guillaumin), traduit et commenté par J.-Y. Guillaumin. París, ALMA, 2009. Para su traducción castellana, véase la de la BAC anteriormente comentada. Es preciso indicar que la edición de la colección ALMA de este libro III, la utilizada en este artículo, no considera el capítulo 14 de la edición clásica de Lindsay (véase Wallace Martin Lindsay: Isidori Hispalensis Episcopi Etymologiarum sive Originum libri XX, recognovit brevique adnotatione critica instruxit [2 vols.], Oxford, OCT, 1971 [1911]). Por tanto, la numeración de los capítulos de esta edición varía en relación a la de Lindsay, siendo un número menos desde ese mismo capítulo 14 en la edición de Gasparotto-Guillaumin que en la edición clásica de Lindsay.

38 "Moisés dice que el inventor del arte de la música fue Túbal, de la estirpe de Caín y que vivió antes del diluvio". Salvo que se indique lo contrario, de aquí en adelante, para las traducciones al castellano del Libro III de las Etimologías, cito la traducción de la BAC.

39 "Tubal, como ya hemos dicho, pasa por ser el inventor de la cítara y del salterio".
} 
Es importante incidir en que, en esta ocasión, estamos hablando de un personaje distinto a Jubal. Según la Biblia (Ge.4.19-22), Lamec de la estirpe de Caín, tomó para sí dos mujeres, Ada y Zila. De la primera nacieron Jabal y Jubal. De la segunda, Tubalcaín (Tubal, de la estirpe de Caín) y Naama. Cada uno de estos hijos varones personifica el origen bíblico de algunas de las más antiguas disciplinas humanas. Jabal fue el padre de los que habitan en tiendas y crían ganados; es decir, fue el creador de la ganadería $(\mathrm{Ge} .4 .20)^{40}$. Jubal, su hermano, fue el padre de todos los que tocan la cítara y el órgano; es decir, fue el padre de la música (Ge.4.21). Por su parte, Tubal fue el artífice de toda obra de bronce y de hierro (Ge.4.22); es decir, el primer herrero, por lo que ha de ser considerado el padre de la metalurgia.

\section{Estado de la cuestión}

Dejando a un lado a Jacques Fontaine, de quien hablaré a continuación, hay que destacar que tan solo dos estudiosos isidorianos se han acercado superficialmente al origen judeocristiano de la música en la obra de Isidoro de Sevilla, no advirtiendo en ningún caso los aspectos que aquí analizamos. Además, estos dos autores publicaron sus trabajos antes de que saliera a la luz la gran obra de Fontaine.

Gurlitt ${ }^{41}$ comenta brevísimamente el origen de la música en la obra de Isidoro sin entrar a analizar su procedencia judeocristiana, no distinguiendo entre Jubal y Tubal (evidencia que refleja el desconocimiento del texto de la Chronica por parte del musicólogo germano) y, además, cometiendo algunos errores importantes $^{42}$. Por su parte, F.J. León Tello ${ }^{43}$ dedica tres páginas (pp. 14-16) a comentar brevemente algunas reflexiones isidorianas sobre el origen de la música y del canto litúrgico. En relación a la noticia que nos ocupa se limita a indicar que Isidoro atribuye a Tubal el origen de la música, por lo que también parece evidente que el autor desconoce las grandes reflexiones isidorianas de la Chronica.

Por su parte, Jacques Fontaine, en su antigua, pero capital obra sobre las artes liberales en Isidoro ${ }^{44}$, se percató de que el obispo hispalense señalaba un origen bíblico para la música, describiendo a Tubal como el creador de la misma. No obstante, debido al carácter y a la temática de su obra, la música ocupa un lugar muy secundario y este aspecto tan solo es tratado de

\footnotetext{
${ }^{40}$ Evidentemente, se trata de un lenguaje totalmente alegórico que, como he dicho, ejemplifica el origen de distintas actividades humanas. Si leemos la Biblia en un sentido literal, Abel, por ejemplo, fue pastor antes que él, y, por tanto, el primer ganadero y padre de la ganadería. En este sentido Jabal solo podría ser considerado el padre de la ganadería nómada.

${ }^{41}$ Wilibald Gurlitt: Zur Bedeutungsgeschichte von musicus und cantor bei Isidor von Sevilla, Mainz, Akademie der Wissenschaften und der Literatur, 1950, pp. 543-558.

${ }^{42}$ Como el atribuir a Aristóxeno la creación de la leyenda del descubrimiento pitagórico de las consonancias musicales, Ibid., p. 549.

${ }^{43}$ Francisco José León Tello: "La teoría musical en las obras de Isidoro de Sevilla", Música (Revista Trimestral de los Conservatorios Españoles), 1, 1952, pp. 11-28.

${ }^{44} \mathrm{~J}$. Fontaine: Isidore de Seville et la culture classique dans L'espagne wisigothique, París, Études Augustiniennes, 1983 (segunda edición revisada y corregida), pp. 421-422.
} 
pasada en un apartado dedicado a la historia de la música que ocupa página y media (pp. 421-422). Fontaine se limita a exponer el hecho sin hacer distinción alguna entre Tubal y Jubal (tan solo habla de Tubal, aun mencionando expresamente también la Chronica isidoriana), sin hacer referencia alguna a la innovación de Isidoro en relación al texto jeronimiano y a la literatura anterior, sin comentar los motivos que conducen al obispo hispalense a realizar tal aportación, y, evidentemente, sin tratar el nuevo cambio isidoriano de las Etimologías.

Sin embargo, y a pesar de lo dicho, lo que resulta más extraño del análisis del estado de la cuestión es que estas innovaciones isidorianas hayan pasado prácticamente inadvertidas para la crítica posterior. Este aspecto es corroborado por Michel Huglo, quien sí comenta esta cuestión superficialmente ${ }^{45}$ en el fragmento más interesante al respecto desde el estudio de Fontaine:

En el De musica, III, xvi, 1, y III, xxii, 2, Isidoro establece un paralelismo entre Tubal, un herrero que utiliza el martillo (malleator), y Pitágoras, autor de la 'ley de los sonidos consonantes' descubierta mientras escuchaba a los herreros trabajar con martillos de distintos pesos. En 615-616, y luego en 626, Isidoro había formulado en el capítulo 14 de sus Crónicas una explicación diferente sobre el origen de la música, atribuyéndola entonces a Jubal; véase Jose Carlos Martín Iglesias, ed. Isidori Hispalensis Chronica.Turnhout: Brepols, 2003 (Corpus Christianorum: Series Latina 112). Agradezco sinceramente al profesor José Carlos Martín que me haya señalado esta variación en el pensamiento de Isidoro, hasta ahora inadvertida para todos los musicólogos.

Por tanto, aunque Huglo no se detiene a analizar esta cuestión, dedicando tan solo esta breve nota al origen cristiano de la música según Isidoro, sí que avisa de que esta situación ha pasado inadvertida para los musicólogos.

\section{Jubal y Tubal. La justificación de la variación isidoriana}

A continuación, voy a exponer los motivos que condujeron a Isidoro a atribuir el origen de la música a Tubal en los pasajes citados de las Etimologías (obra que revisó y modificó hasta su muerte dejándola inconclusa) cuando previamente había hecho lo propio con Jubal en las dos versiones de su Chronica. Partiendo del propio texto isidoriano y de su contexto cultural, se puede esclarecer de una manera bastante certera el porqué de este cambio.

Para empezar, resulta evidente que Isidoro no pudo confundir a estos dos personajes, Jubal y Tubal, por varios motivos. En primer lugar, debido al enorme conocimiento que demuestra tener sobre la Biblia, y especialmente sobre los libros del Antiguo Testamento, tal y como se observa a lo largo de toda su obra. Además, hay que destacar el hecho de que estos dos hermanos, Jubal y Tubal,

\footnotetext{
${ }^{45}$ Michel Huglo: "La tradición de la Musica Isidori en la Península Ibérica", Hispania Vetus. Manuscritos litúrgico-musicales de los orígenes visigóticos a la transición francorromana (siglos IX-XII), Susana Zapke, María José Azevedo Santos (eds.), 15, Bilbao, Fundación BBVA, 2007, pp. 61-93; 85.
} 
aparecen en dos pasajes contiguos del Génesis (4.21-22), por lo que su diferenciación y relación se aprecia claramente con un solo golpe de vista. Por último (y lo más importante), no se debe olvidar que el propio Isidoro los distingue perfectamente en su Chronica (cap. 14, año 1454): Hac quoque aetate Iubal ex genere Cain artem musicam repperit, cuius etiam frater Tubalcain aeris ferrique inuentor fuit ${ }^{46}$.

Por otra parte, es importantísimo señalar que los capítulos del Libro III de las Etimologías dedicados a la música son continuadores de una importante tradición literaria griega y latina de carácter técnico en la que la música es tratada como materia del quadrivium y en la que el peso de la tradición musical griega es abrumador. En la mayoría de los tratados musicales de la época tardoantigua (y en otros muchos anteriores) que, aunque eclécticos, tenían un fuerte influjo del pensamiento musical griego de origen pitagórico y platónico, se transmitieron diferentes leyendas relacionadas con la figura de Pitágoras, entre las que destacó una que atribuía al filósofo de Samos el descubrimiento de las distintas consonancias musicales debido a la inspiración que le llegó tras escuchar el sonido de unos martillos en una fragua. A raíz de ello, el gran filósofo realizó una serie de experimentos que le condujeron al descubrimiento de las distintas consonancias musicales y las proporciones matemáticas que las definen.

Debido al carácter de su texto y a su faceta enciclopedista, Isidoro continúa esta tradición haciendo alusión a esta leyenda, que es copiada literalmente de un texto de Casiodoro (Inst.2.5.1) ${ }^{47}$, quien pone en boca de otro gran teórico de la música anterior, Gaudencio el Filósofo, la noticia de la siguiente manera: Gaudentius quidem, de musica scribens, Pythagoram dicit huius rei invenisse primordia ex malleorum sonitu et cordarum extensione percussa ${ }^{48}$. En efecto, Gaudencio trató este asunto en el capítulo XI de su Introducción a la harmónica, otro de los grandes tratados musicales tardoantiguos ${ }^{49}$. Ni que decir tiene que Isidoro no cono-

46 "También en esta época Jubal, del linaje de Caín, descubrió el arte de la música y su hermano Tubalcaín fue el inventor del bronce y el hierro".

${ }^{47}$ Para la edición crítica de las Instituciones, véase R. A. B. Mynors: Cassiodori Senatoris Instituciones, Oxford, Clarendon Press, 1937. Existe una traducción española de la parte dedicada a las disciplinas liberales (que es la que nos interesa en este trabajo) que no tiene buena calidad y, además, muestra excesiva dependencia de la traducción de las Etimologías ya mencionada en notas anteriores. Dicha traducción se puede ver en Mari Cruz Ramos Torres (trad.): Casiodoro. Institutiones saecularium litterarum. Las siete artes liberales, Valdemorillo, La Hoja del Monte, 2009.

${ }^{48}$ No seguimos aquí la traducción española citada más arriba, ya que contiene un error muy importante que muestra tanto falta de habilidad en la traducción como una falta grave de conocimiento de la materia tratada, pues traduce "Gaudentius quidem, de musica scribens" como "Muy alegremente sin duda, el que escribe sobre música"; por tanto, aporto aquí mi propia traducción basada a su vez en la del idéntico fragmento isidoriano por parte de J. Oroz Reta, M. Casquero en Etym. BAC: "En efecto, Gaudencio, escribiendo sobre música, dice que fue Pitágoras quien echó los cimientos de este arte, inspirándose en el sonido de los martillos y de la percusión de cuerdas tensadas".

${ }^{49}$ Para la edición del texto, véase Karl von Jan: Musici scriptores Graeci. Aristoteles, Euclides, Nicomachus, Bacchius, Gaudentius, Alypius et melodiarum veterum quidquid extat. Recognovit prooemiis et indice instruxit Carolus Janus. Annexae sunt tabulae. Hildesheim, Georg Olms Verlagsbuchhandlun, 1962, pp. 317-356. 
ció el texto de este teórico musical griego y, de hecho, ni siquiera lo menciona en el fragmento citado a pesar de que Casiodoro sí lo hace. La relación con el texto de Casiodoro es la que sigue:

\begin{tabular}{|l|l|}
\hline \multicolumn{1}{|c|}{ Isidoro (Etym.3.15.1) } & \multicolumn{1}{|c|}{ Casiodoro (Inst.2.5.1) } \\
\hline $\begin{array}{l}\text { Graeci uero Pythagoream dicunt huius artis inue- } \\
\text { nisse primordia ex malleorum sonitu et chordarum } \\
\text { extensione percussarum }\end{array}$ & $\begin{array}{l}\text { Gaudentius quidem, de musica scribens, Pythagoram } \\
\text { dicit huius rei invenisse primordia ex malleorum } \\
\text { sonitu et cordarum extensione percussa }\end{array}$ \\
\hline
\end{tabular}

Por último, es preciso indicar un detalle fundamental, Isidoro hace alusión a esta leyenda justo a continuación de la primera referencia que hace sobre Tubal como creador de la música. Es decir, en Etym.3.15.1 se puede leer: Moyses dicit repertorem musicae artis fuisse Tubal, qui fuit de stirpe Cain ante dilunium. Graeci uero Pythagoream dicunt huius artis [refiriéndose, obviamente, a la música] inuenisse primordia ex malleorum sonitu et chordarum extensione percussarum ${ }^{50}$.

Por tanto, teniendo en cuenta todo lo dicho hasta aquí, parece evidente que la variación de los nombres de Jubal y Tubal, atribuyendo el origen de la música a este último, se puede deber a una asimilación de esta leyenda helénica recogida en la mayoría de estos tratados musicales tardoantiguos. Esta postura de la asimilación de la leyenda griega cobra más fuerza si tenemos en cuenta la distribución y la relación existente entre ambos textos, pues, si observamos el discurso de Isidoro, se puede comprobar cómo introduce la distinción del origen de la música para los cristianos (Moyses dicit) y para los paganos (Graeci [...] dicunt). El doctor hispalense sitúa, por tanto, a una figura bíblica en el origen de la música cristiana, contraponiéndolo a una figura de enorme peso en la tradición filosófica y musical pagana, Pitágoras; y establece un único nexo de unión entre ambas: el trabajo con el sonido de los metales, de los martillos de metal (malleorum sonitu).

Una vez considerados estos aspectos, cabe preguntarse por qué Isidoro produce un texto inspirado claramente en esa leyenda pagana de origen griego sobre Pitágoras contradiciéndose a sí mismo en relación a lo que dijo previamente en su Chronica y modificando, incluso, el propio texto bíblico.

Esta pregunta se puede responder mediante la aclaración de una última premisa fundamental: la actitud isidoriana no debe entenderse como una victoria de la cultura pagana sobre la cristiana, pues es evidente, y a pesar de lo que pueda parecer, que para Isidoro no tiene más importancia el crear un relato

\footnotetext{
Para su traducción española véase F. Garrido Domené: Los teóricos menores de la música griega: Euclides el Geómetra, Nicómaco de Gerasa y Gaudencio el Filósofo, Barcelona, Cérix, 2016, pp. 353-369.

50 "Moisés dice que el inventor del arte de la música fue Tubal, de la estirpe de Caín y que vivió antes del diluvio. Por su parte, los griegos afirman que fue Pitágoras quien echó los cimientos de este arte, inspirándose en el sonido de los martillos y de la percusión de cuerdas tensadas".
} 
cristiano equiparable al que transmite la tradición técnica antigua pagana que el propio texto bíblico o la ortodoxia de la propia doctrina cristiana. De hecho, lo que ocurre es más bien lo contrario.

El doctor hispalense, tras comprobar el enorme peso de la figura de Pitágoras en la tradición musical griega y ser consciente de que está escribiendo un libro musical de carácter técnico situado dentro de esa misma tradición, considera necesario anteponer un personaje judeocristiano lo más relacionado posible con el protagonista del enormemente famoso relato transmitido en la literatura grecolatina para poder contrarrestar tanto el relato pitagórico como la propia figura de Pitágoras, aunque para ello tenga que sacrificar su fidelidad al texto bíblico e, incluso, contradecirse a sí mismo ${ }^{51}$.

Por tanto, la verdadera motivación de Isidoro vuelve a ser la que, en esencia, se dio en la Chronica: anteponer la cultura judeocristiana a la pagana, supeditando la segunda a la primera. El obispo hispalense, por un lado, debido al carácter del texto y a su faceta enciclopédica, se ve obligado a transmitir la noticia sobre Pitágoras que leyó en Casiodoro. Sin embargo, por otro lado, como padre de la Iglesia hispanovisigoda, se ve obligado a realizar una pequeña modificación al texto bíblico para conseguir nuevamente la supremacía judeocristiana en el origen y creación de la música, pues, aunque haya perdido fidelidad a la Biblia, el personaje sigue siendo igualmente bíblico, y eso es lo que realmente importa al obispo hispalense.

\section{La conciliación de ambas versiones en el pensamiento histórico- musical isidoriano}

Llegados a este punto, y teniendo en cuenta los motivos que llevaron a Isidoro a describir como el creador de la música, primero, a Jubal y, despúes, a Tubal, cabe preguntarse por qué el obispo hispalense mantuvo estas dos versiones (que, evidentemente, se contradicen) en ambas obras. A mi modo de ver, esta pregunta tiene una clara respuesta: Isidoro adapta su finalidad al carácter de cada texto, la Chronica y el Libro III de las Etimologías y, sobre todo, a los potenciales lectores de cada uno de estos dos textos, muy diferentes entre sí de acuerdo con los contenidos de cada obra. Por tanto, para responder a esta pregunta hay que tener en cuenta la dimensión pedagógica de la obra de Isidoro de Sevilla.

La Chronica es un texto historiográfico en el que Isidoro quiere dejar claro (respetando el marco histórico patrístico de Eusebio-Agustín, ya señalado) que la música tiene un origen bíblico. En este texto es muy importante destacar la importancia histórica de la cultura judeocristiana situándola por encima de la

\footnotetext{
${ }^{51}$ En este sentido, el obispo hispalense cumple con creces su finalidad si hacemos caso a la literatura posterior, pues, como ya he indicado, es el iniciador de una corriente literaria similar que se puede observar en otros textos musicales de carácter técnico en la que Jubal o Tubal son descritos como los creadores de la música.
} 
pagana, por lo que, ante la ausencia de datos en este sentido en el texto de Jerónimo, Isidoro se ve obligado a acudir al texto bíblico que tan bien conocía, utilizándolo como base para atribuir ese origen bíblico a la música. Tan solo tiene que recoger la noticia bíblica e incluirla en su obra respetando su propia concepción historiográfica y la cronología marcada por su contexto cultural.

Por su parte, el Libro III de las Etimologías es un texto de carácter técnico, heredero directo de otros tardoantiguos que a su vez se basan en otros anteriores cuyas ideas, en muchos casos, tienen un claro origen pitagórico y platónico. En estos textos el peso de la tradición musical grecorromana es capital, ocupando la figura de Pitágoras un lugar fundamental. Asociadas al maestro fundador, los pitagóricos transmitieron una serie de leyendas que se convirtieron en lugar común de prácticamente toda esta literatura musical de carácter técnico, destacando entre todas la ya referida. Ante esta situación, y para contrarrestar la fama del relato pagano, Isidoro tiene claro que ha de anteponer un personaje cristiano de características similares a las del transmitido en la tradición grecolatina, aunque para ello tenga que perder fidelidad en relación al texto bíblico. La solución es original y efectiva: atribuir a Tubal, herrero y fundador de la metalurgia, el origen de la música.

Por tanto, Isidoro consigue en estas dos obras su propósito: justificar el origen de la música desde el punto de vista bíblico, respetando, a su vez, la naturaleza, la tradición y los contenidos tan diferentes de las dos obras referidas y, sobre todo, teniendo siempre en cuenta a los potenciales lectores de dichas obras, a los que tendrá que justificar ese origen cristiano de la música con argumentos que se adapten a sus diversas culturas, intereses y sensibilidades. 